\title{
A Review on Progress of Bagasse and Coir Fibre Composites and Their Mechanical Performances
}

\author{
Er. Sanjib Kumar Koley ${ }^{1 *}$, Er. Lakshya Aggarwal ${ }^{2}$, Dr. Ravinder Singh Joshi ${ }^{3}$, \\ Dr. Bikram Jit Singh ${ }^{4}$ \\ ${ }^{I}$ M.Tech. (Mechanical Engineering) Student from M.M. University, Sadopur, Ambala, Haryana, India \\ Email:sanjibkumarkoley@yahoo.com ("corresponding author) \\ ${ }^{2,3}$ Associate Professor of Mechanical Engineering, M.M. University, Sadopur, Ambala, Haryana, India \\ ${ }^{4}$ Professor and HOD of Mechanical Engineering, M.M. University, Sadopur, Ambala, Haryana, India
}

\begin{abstract}
The main objective of this review is to study the potential of agro-residues such as bagasse fibre, coir fibre, and combination of both as reinforcements for composite materials as an alternative to natural and synthetic fiber. In recent times, there has been a fast progress in study and development in the field of natural fibre composite. Interest is justified due to the reward of these materials compared to synthetic fibre composite, including unassuming environmental strength, inexpensive and hold up their prospective across a extensive range of use. A lot of effort has been made in ordered to examine the mechanical properties of composites made from these natural fibre materials. This study aims to offer a summary of the factors that influence the mechanical properties of natural fibre composites particularly in bagasse and coir fibre composite and their hybrid composites.
\end{abstract}

Keywords: bagasse, coir, composite, fiber, hybrid

\section{Introduction}

In recent time, major efforts have been directed to investigate the use of natural fibres as reinforcement in thermoplastics. Natural fibres, for example wood fibre, bagasse fibre, coir fibre, wheat straw, jute fibre and rice husk have several benefits i.e. low cost, low density, high toughness, acceptable specific strength, biodegradability and enhanced energy recovery. The natural fibre uses in plastic matrix have a lot of benefits, for instance low cost, increase of stiffness of thermoplastics, increase of heat deflection temperature, and improvement of surface exterior [1]. The sugarcane bagasse (SCB) is a residue extensively generated in high extent in the agro-industry. A fibrous residue of sugarcane stalks is surplus after the crushing and extraction of juice from the sugarcane. This sugar industry by-product is almost fully used as fuel for the boilers by the sugarcane factories. The bagasse is a natural fiber generally constituted by cellulose i.e. glucose-polymer with relatively high modulus [2]. The coconut husk is obtainable in bulk as remainder from coconut in most of the places, which is the coarse coir fiber. It is obtained from the outer shell of coconut, or husk of the coconut. The husk comprises of $30 \mathrm{wt} \%$ coir fibers and $70 \mathrm{wt} \%$ pith. Coconut coir is the most attractive products as its lowest bulk density and thermal conductivity. The addition of coconut coir in composite reduces the thermal conductivity of the composite and produce a light weight product. Development of composite materials for buildings is using natural fiber as coconut coir with low thermal conductivity and biodegradability [3]. Natural fibre composites comprise, high specific strength and stiffness and low density. Fibres are a renewable resource, for which production requires small energy, carbon dioxide absorption, and oxygen returning to the environment. Cost of production of fibres is lesser than synthetic fibres. Hazard in manufacturing processes is less. When subjected to heat and during incineration at end of life emitted low toxic fumes. Natural fibres compared to synthetic fibre composites have less abrasive damage to processing equipment [4].

\section{Review of Mechanical Performances of Bagasse and Coir Fibre Composites}

Brahmakumar et al [5] used coconut fibre as reinforcement material in low density poly-ethylene (LDPE) in his investigation. The natural waxy surface layer of coconut fibre provided a strong interfacial bonding between the fibre and the polyethylene matrix. When the critical fibre length doubled, the composite tensile strength and modulus decreases by $40 \%$ and $60 \%$. Because of its polymeric nature the waxy layer showed a stronger effect on fibre/matrix bonding. By incorporating 0.25 volume fraction (vf) of $20 \mathrm{~mm}$ long fibre the longitudinal tensile strength and modulus of coconut fibre composite improves by about 3 times and 7 times respectively.

Cao et al [6] developed the biodegradable aliphatic polyester composites and use bagasse fibres as reinforced material. With increase in fibre content both the tensile strength and impact strength of the untreated bagasse fibre composites increased to an optimum fibre content of 65\%. SEM micrographs discovered that the compressed cellulose structure of the bagasse fibre could have contributed to the improvement in these 
properties. The Na-OH (1\%) treated fibre composites showed maximum improvement in $13 \%$ in tensile strength, $30 \%$ in impact strength and $14 \%$ in flexural strength rather the $\mathrm{Na}-\mathrm{OH}(3$ and $5 \%$ ) treated fibre composites.

Rahman and Khan [7] studied coir fibers with acrylate monomer i.e. ethylene-di meth acrylate (EMA). For low cost composites, due to the economic and environmental advantages coir fibre can be used as reinforcing materials. A useful composite having good strength could be effectively developed by using coir fibers as a reinforcing source for the poly meth acrylate matrix. It was observed after treatment of the fibers a significant increase in the strength of the composites. UV pretreatment of the coir showed an increase of tensile properties due to inter cross linking. For the $20 \%$ alkali treated followed by grafting with $50 \%$ EMA, the best improvement was observed. Alkali treatment of coir fiber also decreased the hydrophilicity of the fiber and considerable increase of tensile properties of the grafted fiber was also observed.

Tayeb [8] investigated the adhesive friction and wear characteristics of sugar cane fibre reinforced polyester (SCRP) and glass fibre reinforced polyester (GRP) composites sliding against smooth counter face. It has been found that when sliding against stainless steel, SCRP composite offers a good degree of wear resistance and friction coefficient compare to GRP. Hence, sugarcane fibre has a strong prospective to reinforce polyester and proved to be a quite competitive to glass fibre. In general, friction coefficient decreases with increasing load for both chopped and unidirectional fibers reinforced polyester composites. Sugarcane fibre (SCF) being nonabrasive fibre whereas glass fibre (GF) being abrasive fibre, both contributed in a different way to the wear process at the interface. The comparatively soft and non-abrasive nature of SCF and the ability to deform bend well under sliding conditions without cracking, hence make it suitable for reinforcement.

Luz et al [9] worked on polypropylene (PP) composites reinforced with sugarcane bagasse (SCB). The adding up of fibers to the matrix in composites resulted inferior tensile strength compared to neat PP. Composites were more brittle than matrix. The tensile modulus indicated that only cellulose $20 \mathrm{wt} \% / \mathrm{PP}$ and cellulignin 20 wt\%/PP composites were more rigid than neat PP and other composites, though, the flexural properties of composites were greater than those ones of neat PP. Thermo gravimetric analysis showed that the composites based on untreated and treated cellulose and cellulignin presented intermediary stability in respect to matrix and fiber. DSC results showed that the composites reinforced with untreated fibers were more crystalline. The acetylation was not an efficient process for treatment of fibers as the mechanical properties reduced with the acetylation.

Monteiro et al [10] described the composite of independently unfastened coir fibers with unsaturated orthoftalic polyester resin and 1wt\% of methyl-ethyl-ketone (catalyst) as matrix. Arbitrary oriented coir fiber polyester composites are low strength materials, but can be designed to have a set of flexural strengths. The lack of an efficient reinforcement by coir fibers is leaded to their poor modulus of elasticity, in associate with that of the exposed polyester resin. With the fabrication route used two dissimilar products were obtained, i.e. rigid composites, for fiber loading below $50 \% \mathrm{wt}$, and agglomerates, when the fiber loading was beyond $50 \% \mathrm{wt}$.

Vilay et al [11] conducted investigation on the composite prepared of bagasse and unsaturated polyester matrix. Higher tensile and flexural properties were obtained for treated fiber composites compared to untreated fiber based composites. Chemical treatments via $\mathrm{Na}-\mathrm{OH}$ and acrylic acid (AA) reduced the water absorption of composites, and increased the storage modulus and transition time of the composites.

Harish et al [12] reported coir/epoxy composites show average values on behalf of the tensile strength, impact strength and flexural strength of $17.86 \mathrm{MPa}, 11.49 \mathrm{KJ} / \mathrm{M}^{2}$ and $31.08 \mathrm{MPa}$ respectively. These values are considerably lesser than those considered for glass fiber reinforced plastics (GFRP) laminate specimens.

Mulinari et al [13] used sugarcane bagasse cellulose as well as sugarcane bagasse cellulose modified with zirconium oxy chloride $(\mathrm{ZrOCl} 2-8 \mathrm{H} 2 \mathrm{O})$ was mixed with the polymeric matrix high density poly-ethylene (HDPE). The modification of sugarcane bagasse cellulose with zirconium oxy chloride was effectively accomplished and it was confirmed that efficiently improves the tensile strength compared to non-modified sugarcane bagasse cellulose. The modification of sugarcane bagasse cellulose decreased the composites elongation to $26 \%$ compared to non-modified sugarcane bagasse cellulose; on the other hand the tensile modulus increased $50 \%$.

Pinto et al [14] investigated the composite comprises of poly hydroxyl butyrate (PHB) and sugarcane bagasse fibers. Function of both the compressive/molding pressure and incorporation of bagasse fibers changed the properties along with structure of PHB. Rising pressure raised the spherulite size beginning since the molten state. This is ascribed to the grain boundary. In contrast, incorporation of bagasse fibers reduced the spherulite size. The lattice parameters and the PHB volume unit cells reduced with rising pressure till 6 tons. This is accredited to the alteration in packing pattern in the unit cell of the polymer from 4 to 6 tons. Thermal transitions took place with growing pressure, as indicted by the nonexistence of one peak in DSC curves of PHB. Incorporation of bagasse fibers reduced the brittleness of PHB at low temperature.

Rosa et al [15] analyzed the mechanical properties of poly ethylene-co-vinyl alcohol copolymer (EVOH) reinforced with coconut fiber composite after fiber treatments by washing, bleaching and mercerization. All 
these treatments removed surface impurities and improving thermal stability of fiber-reinforced composites as per SEM analyses. The composites made with mercerized fibers showed a considerable $33 \%$ improvement in tensile strength and a 75\% improvement in tensile modulus than the neat starch/EVOH. Hence the starch/EVOH blends reinforced with treated coconut fibers have better characteristics than pure starch/EVOH blends.

Wei and Gu [16] investigated tensile strength of the composites of coir fibre as the reinforcement and the rubber as matrix. The coir/rubber composite with the fibre volume fraction of $60 \%$ was fabricated by using the heat press technique. During the heat press process the temperature variation $\left(130-160^{\circ} \mathrm{C}\right)$ has no considerable influence on the composites as far as tensile strength was concerned. Coir fibre volume fraction of $60 \%$ would be the maximum tensile strength of the composites.

Guimaraes et al [17] compared the composite prepared by sugarcane bagasse fibers and banana fibers as reinforced material and the starch as matrix. Fractographs of bagasse fiber composites compared with banana fiber composites, showed a great number of fiber pull-outs and fibers lying perpendicular to the fracture surface, and these appeared to explain the tendencies observed in their tensile properties. Good bonding between the bagasse fibers and the matrix was shown by the starch coating on these fibers, compared to the free surface of banana fibers.

\section{Recent Progresses of Mechanical Performances of Bagasse and Coir Fibre Composites}

Brugnago et al [18] carried out study on composite of polyester matrix and sugarcane bagasse. The amalgamation of steam-exploded fibers in unsaturated polyester had a constructive reinforcing effect w.r.t. DMA analysis with higher thermal stability compared to composites comprises bagasse fibers. This is because of the better compatibility of these fibers with the polyester matrix than that of high substance of a modified lignin that is insecurely connected to the matrix.

Cerqueira et al [19] studied polypropylene (PP) and sugarcane bagasse composite, utilizing the agro-residue as alternative reinforcement in thermoplastics and to demonstrate the effect of modification on the mechanical properties of the composites chemical modification of cellulose fibers from sugarcane bagasse. It was confirmed that effectively improves the tensile, flexural and impact strength in comparison to the neat polymer.

Muensri et al [20] fabricated the composite of gluten materials reinforced with coconut fiber. The properties of coconut coir/wheat gluten biocomposites are considerably different than pure plasticized gluten materials. The mechanical properties of coconut fiber did not modify for lignin content in the fibers between 42 and 21 wt. \% but slightly decreased the water absorption. Hence the remaining lignin is still enough to cover the fiber surface. Therefore it is not a necessary condition to obtain a good fiber/matrix adhesion needed high lignin content in natural fiber/protein.

Gilfillana et al [21] composites of potato starch or hydroxyl propylated maize starch with sugar cane bagasse fibre. It was confirmed that addition bagasse fibre increased the Young's modulus, and for the films containing $5 \mathrm{wt} \%$ fibre, the tensile strength of the materials was also improved. There was a light drop in moisture uptake with fibre addition due to increased bulk crystallinity of the materials. The quantity of moisture content in the films considerably impacted on the mechanical properties of the films because of its weakening effects.

Hemsri et al [22] used coconut fiber (CCF)-reinforced wheat gluten (WG) biocomposites to fabricate composite. The interfacial adhesion between the fibers and WG affects the mechanical properties of the composites. With a carbamate silane surface treatment of fiber can improve WG matrix/coconut fiber adhesion. Alkali treatment lightly enhanced surface adhesion by removing impurities, the hemicellulose, and lignin covering the CCF surface, thereby making a rough surface topography of alkali-treated fiber (ACCF). Considerable improvements in mechanical properties were obtained by following the alkali surface treatment with the silane treatment on the fiber. The improved adhesion in the alkali-followed by silane-treated fiber (ASCCF) reinforced WG led to a approximately 25\% increase in the stress at the first failure point on the stress/strain curve and a more or less $80 \%$ increase in the maximum stress. The improved adhesion also reduced the fiber pullout lengths experienced on the failure surfaces of tensile test.

Huang et al [23] used the untreated and differently treated sugar cane bagasse (SCB) to produce composites with poly vinyl chloride (PVC) as polymer matrix. For the unmodified SCB/PVC composites, the split and demolition of the firm structure of SCB fibres, reduce in element size and deteriorating of hydrogen bonds induced by intensive milling appreciably increased the interfacial bonding between SCB and PVC matrix, which were visibly observed by the SEM photographs of fractured surfaces for microstructure of the composites reinforced with unmilled and 120 min milled SCBs. The superior interfacial bonding between milled SCB and PVC obviously improved the mechanical properties of the composites.

Agunsoye and Aigbodion [24] fabricated bagasse filled recycled polyethylene bio-composites by compounding and compressive molding. The consistent distribution of the bagasse particles in the microstructure of the polymer composites is the most important factor accountable for the enhancement in the mechanical properties. The bagasse particles added to the recycled low density poly-ethylene (RLDPE) polymer enhanced its rigidity and hardness of the composites. With increasing percentage of the bagasse to maximum of 20 wt $\%$ 
uncarbonized (UBp) and $30 \mathrm{wt} \%$ carbonized (CBp) the tensile and bending strengths of the composite increased. At the ranges of $30 \mathrm{wt} \%$ bagasse additions, the developed composites have better properties. For optimum service condition, carbonized bagasse particles addition should be within $30 \mathrm{wt} \%$.

Arrakhiz et al [25] investigated the mechanical properties of alfa, coir and bagasse fibers reinforced polypropylene (PP) composites. Prior compounding, alfa, coir and bagasse fiber reinforced PP composites the fibers were subjected to an alkali treatment $(8 \mathrm{wt} . \%)$ to take out waxes and other non-cellulosic components to raise their compatibility with the PP matrix. The chemically treated fibers composites yielded improved mechanical properties compared to neat PP to their tensile, flexural and torsional properties. A considerable enhance in mechanical properties of composites is obtained with increasing fiber loading. It is observed that composites with a $30 \mathrm{wt}$. \% fiber content shows the optimum set of mechanical properties, the fiber type having no effects.

Sivaraj and Rajeshkumar [26] conducted the comparison of tensile, flexural and impact strength for various mixture ratio of coir and bagasse fiber contents with polymer resin and the optimal mixing of fibers weight ratio were designed for the effective tensile strength, flexural strength and impact energy. The $30 \%$ of coir fiber and $10 \%$ of bagasse fiber with $60 \%$ of polyester resin obtained the best values of tensile strength, flexural strength and impact energy i.e., $26.45 \mathrm{MPa}, 44.31 \mathrm{MPa}$ and $4.5 \mathrm{~J}$ respectively. The testing results were tabulated for corresponding fiber weight ratio in Table.

Table: Mechanical properties of composites

\begin{tabular}{|c|c|c|c|c|c|}
\hline $\begin{array}{c}\text { Sample } \\
\text { Identification }\end{array}$ & $\begin{array}{c}\text { A } \\
\text { Coir } \\
(\%) \\
\end{array}$ & $\begin{array}{c}\text { B } \\
\text { Bagasse } \\
(\%)\end{array}$ & $\begin{array}{c}\text { Tensile } \\
\text { Strength } \\
(\mathrm{MPa})\end{array}$ & $\begin{array}{c}\text { Flexural } \\
\text { Strength } \\
(\mathrm{MPa})\end{array}$ & $\begin{array}{c}\text { Impact } \\
\text { Energy } \\
(\mathrm{J})\end{array}$ \\
\hline S1 & 10 & 10 & 15.83 & 35.84 & 3.5 \\
\hline S2 & 20 & 10 & 22.13 & 42.64 & 4.1 \\
\hline S3 & 30 & 10 & 26.45 & 44.31 & 4.5 \\
\hline S4 & 10 & 20 & 17.69 & 37.36 & 3.0 \\
\hline S5 & 20 & 20 & 22.60 & 43.12 & 3.2 \\
\hline S6 & 30 & 20 & 23.42 & 44.20 & 4.2 \\
\hline S7 & 10 & 30 & 12.52 & 30.84 & 3.0 \\
\hline S8 & 20 & 30 & 16.83 & 34.18 & 3.3 \\
\hline S9 & 30 & 30 & 18.72 & 37.98 & 4.0 \\
\hline
\end{tabular}

From the SEM test, it is understood that there is no pull out holes on the specimens rather the breaking of fibers only found out. Hence the bonding between fibers and polyester resin was enormously high.

\section{Conclusions}

To a great extent research and developments has occurred on progress of bagasse and coir fibre composites and their mechanical performances. Improvement has occurred due to improved fibre selection, extraction, treatment and interfacial engineering as well as composite processing. This paper has reviewed the research that has focused on improvement of tensile strength, flexural strength, impact strength and hardness of bagasse and coir based hybrid composites. Applications of bagasse and coir based hybrid composites have extended dramatically including load bearing and outdoor applications such as automotive exterior under floor paneling, sports equipment and aircraft structures. Further research is still required to extend their application range including improvement of ultimate tensile strength, flexural strength, impact strength and hardness of hybrid composites. Overall, growth of bagasse and coir based hybrid composites uptake continues at a speedy rate and there would emerge to be a very positive future ahead for their application.

\section{Acknowledgements}

It is with a feeling of great pleasure that I would like to express my most sincere heartfelt gratitude to Er. Lakshya Aggarwal Associate Professor, M.M. University, Sadopur, Ambala and Dr. Ravinder Singh Joshi Associate Professor, M.M. University, Sadopur, Ambala for their ready and able guidance all over the course of my preparing the review paper. I am greatly indebted to them for their constructive suggestions and criticism from time to time during my M. Tech. course. Their in-depth knowledge on composite materials has been extremely beneficial for me. I express my sincere thanks to Dr. Bikramjit Singh Professor and Head of Mechanical Engineering Department, M.M. University, Sadopur, Ambala for providing me the necessary facilities in the department. I also thank all those who have directly involved or indirectly helped for this work.

\section{References}

[1] Y. T. Zheng, D. R. Cao, D. S. Wang, and J. J. Chen, Study on the interface modification of bagasse fibre and the mechanical properties of its composite with PVC, Journal of Composites: Part A, 38(1), 2007 20-25.

[2] S. M. Luz, A. R. Goncalves, and A. P. Del'Arco Jr, Mechanical behavior and micro structural analysis of sugarcane bagasse fibers reinforced polypropylene, Journal of Composites: Part A, 38, 2007, 1455-1461. 
[3] A. Chanakan, C. Sarocha, H. Jongjit, and K. Joseph, Materials and mechanical properties of pretreated coir-based green composites Journal of Composites: Part B, 40, 2009, 633-637.

[4] K. L. Pickering, M. G. A. Efendy, and T. M. Le, A review of recent developments in natural fibre composites and their mechanical performance, Composites: Part A, 83, 2016, 98-112.

[5] M. Brahmakumar, C. Pavithran, and R. M. Pillai, Coconut fibre reinforced polyethylene composites effect of natural waxy surface layer of the fibre on fibre matrix interfacial bonding and strength of composites, Journal of Composites Science and Technology, 6 , 2005, 563-569.

[6] Y. Cao, S. Shibata, and I. Fukumoto, Mechanical properties of biodegradable composites reinforced with bagasse fibre before and after alkali treatments, Journal of Composites: Part A, 37, 2006, 423-429.

[7] M. M. Rahman, M. A. Khan, Surface treatment of coir (Cocos nucifera) fibers and its influence on the fibers physico-mechanical properties, Journal of Composites Science and Technology 67, 2007, 2369-2376.

[8] N.S.M. El-Tayeb, A study on the potential of sugarcane fibers polyester composite for tribological applications, Journal of Wear, 265, 2008, 223-235.

[9] S. M. Luz, J. Del Tio, G. J. M. Rocha, A. R. Gon Calves, and A. P. Del' Arco Jr., Cellulose and cellulignin from sugarcane bagasse reinforced polypropylene composites Effect of acetylation on mechanical and thermal properties, Journal of Composites: Part A, 39, 2008, 1362-1369.

[10] S.N. Monteiro, L. A. H. Terrones, and J. R. M. D’Almeida, Mechanical performance of coir fiber polyester composites, Journal of Polymer Testing, 27, 2008, 591-595.

[11] V. Vilay, M. Mariatti, R. M. Taib, and M. Todo, Effect of fiber surface treatment and fiber loading on the properties of bagasse fiber-reinforced unsaturated polyester composites, Journal of Composites Science and Technology, 68, 2008, 631-638.

[12] S. Harish, D. P. Michael, A. Bensely, D. Mohan Lal, and A. Rajadurai, Mechanical property evaluation of natural fiber coir composite, Journal of Materials Characterization, 60, 2009, 44-49.

[13] D. R. Mulinari, H. J. C. Voorwald, M. O. H. Cioffi, M. L. C. P. da Silva, T. G. da Cruz, and C. Saron, Sugarcane bagasse cellulose HDPE composites obtained by extrusion, Journal of Composites Science and Technology, 69(2), 2009, 214-219.

[14] C. E. da S. Pinto, G. G. C. Arizaga, F. Wypych, L. P. Ramos, and K. G. Satyanarayana, Studies of the effect of molding pressure and incorporation of sugarcane bagasse fibers on the structure and properties of poly (hydroxy butyrate), Journal of Composites: Part A, 40, 2009, 573-582.

[15] M. F. Rosa, B. S. Chiou, E. S. Medeiros, D. F. Wood, T. G. Williams, L. H. C. Mattoso, W. J. Orts, and S. H. Imam, Effect of fiber treatments on tensile and thermal properties of starch/ethylene vinyl alcohol copolymers/coir bio composites , Journal of Bio resource Technology, 100, 2009, 5196-5202.

[16] W. Wei, and H. Gu, Characterisation and utilization of natural coconut fibres composites, Journal of Materials and Design, 30, 2009, 2741-2744.

[17] J. L. Guimaraes, F. Wypych, C. K. Saul, L. P. Ramos, and K. G. Satyanarayana, Studies of the processing and characterization of corn starch and its composites, Journal of Carbohydrate Polymers, 80, 2010, 130-138.

[18] R. J. Brugnago, K. G. Satyanarayana, and F. Wypych, The effect of steam explosion on the production of sugarcane bagasse polyester composites, Journal of Composites: Part A, 42, 2011, 364-370.

[19] E. F. Cerqueira, C. A. R. P. Baptista, and D. R. Mulinari, Mechanical behaviour of polypropylene reinforced sugarcane bagasse fibers composites, Journal of Procedia Engineering, 10, 2011, 2046-2051.

[20] P. Muensri, T. Kunanopparat, P. Menut, and S. Siri, Effect of lignin removal on the properties of coconut coir fiber, Journal of Composites: Part A, 42, 2011, 173-179.

[21] W. N. Gilfillana, D. M. T. Nguyen, P. A. Sopade, and W. O. S. Doherty, Preparation and characterisation of composites from starch and sugar cane fibre, Journal of Industrial Crops and Products, 40, 2012, 45- 54

[22] S. Hemsri, K. Grieco, A. D. Asandei, R. S. Parnas, Wheat gluten composites reinforced with coconut fiber, Journal of Composites: Part A, 43, 2012, 1160-1168.

[23] Z. Huang, N. Wang, Y. Zhang, H. Hu, and Y. Luo, Effect of mechanical activation pretreatment on the properties of sugarcane bagasse poly (vinyl chloride) composites, Journal of Composites: Part A, 43, 2012, 114-120.

[24] J. O. Agunsoye, and V. S. Aigbodion, Bagasse filled recycled polyethylene bio-composites Morphological and mechanical properties study, Journal of Results in Physics, 3, 2013, 187-194.

[25] F. Z. Arrakhiz, M. Malha, R. Bouhfid, K. Benmoussa, and A. Qaiss, Tensile, flexural and torsional properties of chemically treated alfa, coir and bagasse reinforced polypropylene, Journal of Composites: Part B, 47, 2013, 35-41.

[26] P. Sivaraj, and G. Rajeshkumar, Prediction of Mechanical Properties of Hybrid Fiber Reinforced Polymer Composite, International Journal of Engineering Research 3(1), 2014, 21-25. 